\title{
Lactate Influences the Gene Expression Profile of Human Mesenchymal Stem Cells (hMSC) in a Dose Dependant Manner
}

\author{
Carl-Christoph Schneider ${ }^{a, d}$ Atesch Ateschrang ${ }^{a, b, d}$ Ingmar Königsrainer ${ }^{a} \quad$ Jörg Glatzle ${ }^{a}$ \\ Sarah Bühler ${ }^{c}$ Richard Schaefer ${ }^{c}$ Hinnak Northoffc ${ }^{c}$ Alfred Königsrainer ${ }^{a}$ Derek Zieker ${ }^{a, c}$ \\ aDepartment of General, Visceral and Transplant Surgery, Comprehensive Cancer Center, Tuebingen; \\ bDepartment of Traumatology and Reconstructive Surgery, BG-Trauma and Medical Centre, Tuebingen; \\ 'Department of Transfusion Medicine, Tuebingen; ${ }^{\mathrm{d} T h e}$ first two authors contributed equally to this \\ work
}

\section{Key Words}

Lactate $\cdot$ Human mesenchymal stem cells (hMSC) • Gene expression profile • WEE1 • GAP43 - TSPAN2 - TSPAN13

\begin{abstract}
Background/Aims: Wounds, especially non-healing wounds are characterized by elevated tissue lactate concentrations. Lactate is known for being able to stimulate collagen synthesis and vessel growth. Lately it has been shown that lactate, in vivo, plays an important role in homing of stem cells. With this work we aimed to show the influence of lactate on the gene expressionprofile of human mesenchymal stem cells (hMSC). Materials and Methods: hMSCs were obtained from bone marrow and characterized with fluorescence-activated cell sorting (FACS) analysis. Subsequently the hMSCs were treated with either 0, 5, 10 and $15 \mathrm{mM}$ lactate $(\mathrm{pH} \mathrm{7,4)}$ for 24 hours. RNA Isolation from stimulated hMSCs and controls was performed. The Microarray analysis was performed using AffymetrixHuGene 1.0 ST Gene Chip. Selected targets were subsequently analysed using quantitative real time PCR (RTq-PCR). Results: We were able to show that lactate in moderate concentrations of 5 respectively $10 \mathrm{mM}$ leads to an anti-inflammatory, anti-apoptotic but growth and proliferation promoting gene expression after $24 \mathrm{~h}$. In contrast, high lactate concentrations of $15 \mathrm{mM}$ leads to the opposed effect, namely promoting inflammation and apoptosis. Hypoxia induced genes did not show any significant regulation. Contrary to expectation, we were not able to show any significant regulation of candidates associated with glycolysis. Conclusion: We were able to show that lactate alters gene expression but does not change the cell phenotype, which might be helpful for further investigations of new treatment strategies for chronic non-healing wounds as well as tumor-therapy and neuronal plasticity.
\end{abstract}




\section{Introduction}

Wounds, especially non-healing wounds are characterized by elevated tissue lactate concentrations [1]. In the past accumulation of lactate was thought to be the result of tissue hypoxia, and therefore considered a redundant metabolic by-product. Today some authors even speak of "lacterome" because of the multiple, hormone-like functions of lactate [2]. It has also been shown that the oxygen supply has little impact on the lactate concentration [3]. Wound lactate levels remain high (5-15 mM) even under sufficient oxygenation [4]. Two well known effects of lactate are the stimulation of collagen synthesis [5] and vascular endothelial growth factor induced new vessel growth [6] in vitro and in vivo. More recently Milovanova et al. demonstrated that lactate stimulates vasculogenic stem cells through an autocrine activation loop [7]. Human mesenchymal stem cells are multipotent cells, which are present in adult bone marrow and multiple other tissues. hMSCs can differentiate to various mesenchymal tissues like bone, fat or marrow stroma [8].

The link between wound healing and human mesenchymal stem cells (hMSC) has become a focus of attention lately. It has been shown that wound repair and even reconstitution of the wound bed can be accelerated by multipotent adult stem cells [9]. This study aimed to show the influence of lactate on the gene expressionprofile of human mesenchymal stem cells (hMSC).

\section{Materials and Methods}

\section{Cell Culture}

This study has been approved by the local institutional ethics committee. The bone marrow was obtained under sterile conditions in sterile heparinised syringes. The isolation of the hMSCs was performed with BiotestLymphoflot $\odot$ (Lymphoflot $\odot$, Biotest, Dreireich, Germany). The hMSCs were incubated under standard conditions $\left(37^{\circ} \mathrm{C}, 95 \%\right.$ air, $\left.5 \% \mathrm{CO}_{2}\right)$ with Lonza Medium MEM Alpha Eagle (MEM Alpha Eagle, Lonza, Walkersville Inc., USA). The medium was changed every 24 hours and non-adherent cells were removed. The characterization of the cultivated adherent cells was performed with fluorescence-activated cell sorting (FACS) analysis. Subsequently the obtained and characterized hMSCs were treated with the above mentioned Lonza MEM Alpha Eagle Medium supplemented with either 5, 10 and $15 \mathrm{mM}$ lactate (pH 7,4) (1-lactate, Sigma Aldrich, Deisenhofen, Germany) for 24 hours. hMSCs incubated in the above mentioned media without lactate served as controls.

\section{RNA Isolation}

RNA from stimulated hMSCs and controls was extracted using QiagenRNeasy@ Kit (Qiagen, Hilden, Germany) according to the manufacturer's instructions. The RNA quality and quantity were verified using the Agilent 2100 Bioanalyzer (Agilent Technologies, Palo Alto, USA) and the NanoDrop ND-1000 spectrophotometer (PeqLab Biotechnologies, Germany).

\section{Microarray data generation and statistical analysis}

The microarray analysis was performed at the Microarray Facility Tübingen (MFT, Calwerstr.7, 72076 Tübingen, Germany) using Affymetrix Whole Transcirpt Sense Target Labeling Kit and AffymetrixHuGene 1.0 ST Gene Chip (Affymetrix, Germany). The lactate-stimulated hMSCs were compared with their corresponding controls after 24 hours of treatment. Statistical and bioinformatic analyses were performed using R-language 2.8.1 (www.r-project.org) and bioconductor packages , affy“, , affyPLM“, affyQCReport“ and „ROC“ from Bioconducotor project (www.bioconductor.org).

For the quality control, the non-normalized arrays were used to create a linear model resulting in normalized, not scaled standard error (NUSE), relative logarithmic expression (RLE) as well as signal distribution of all summarized signals after normalization. In addition a positive (exon-based) and negative (intron-based) control probe Receiver-Operator-Characteristics for each array was created.

The background fluorescence was detected with antigenomic background probes.

As a result of the normalization, for each condition the $\log 2$ ratio of the fold change of the lactate-stimulated hMSCs versus their respective controls was computed as criteria for differential gene expression.

FACS analysis

FACS analysis was performed with FACScan (BD Biosciences, San Jose, USA) using BD CellQuest Pro software. At subconfluency ( $1 \times 10^{6}$ cells), the cells were detached with Accutase (PAA Laboratories, Cölbe, Germany) and washed (phosphate-buffered saline (PBS) + AccuMax (PAA Laboratories, Cölbe, Germany). 
Table 1. FACS analysis h68 MSC

\begin{tabular}{l|llllllllllllllllllllllll}
\hline $\mathrm{CD}$ & 4 & 8 & 14 & 29 & 34 & 43 & 44 & 45 & 56 & 59 & 71 & 73 & 90 & 105 & 106 & 117 & 135 & 146 & 166 & 271 & GD2 & HLA ABC & HLA RPQ \\
$\%$ & 32 & $<5,0$ & $<5,0$ & 100 & $<5,0$ & $<5,0$ & 98 & 6 & 8 & 99 & 22 & 96 & 100 & 98 & 95 & 13 & $<5,0$ & 79 & 87 & 30 & 83 & 96 & $<5,0$ \\
\hline
\end{tabular}

Table 2. Primer / Sequence / Oligo Name (Sigma Aldrich)

\begin{tabular}{|c|c|c|c|c|c|}
\hline Primer/SIGMA & Sequence & $\begin{array}{l}\mathrm{TM} \\
{ }^{\circ} \mathrm{C}\end{array}$ & $\begin{array}{l}\text { Annealing } \\
{ }^{\circ} \mathrm{C}\end{array}$ & Oligo Name & $\begin{array}{l}\mathrm{MgCl} \\
\mathrm{mM}\end{array}$ \\
\hline HIF 1 a S & 5-CAACCTTCAGTGTGGGTATAAG-3 & 63,4 & 62 & NM_001530 & 3 \\
\hline HIF $1 \mathrm{a}$ AS & 5-AAATTTCATATCCAGGCTGTG-3 & 66,7 & 62 & NM_001530 & 3 \\
\hline PGK1 S & 5-CATACCTGCTGGCTGGATGG-3 & 67,7 & 62 & NM_000291 & 3 \\
\hline PGK1 AS & 5-CCCACAGGACCATTCCACAC-3 & 67,7 & 62 & NM_000291 & 3 \\
\hline TGF $ß 1 \mathrm{~S}$ & 5-САAGССТССССТССАССАСТ-3 & 72,2 & 62 & NM_000660 & 3 \\
\hline TGF ß1 AS & 5-TGCCGAGAGCGCGAACAGG-3 & 74,4 & 62 & NM_000660 & 3 \\
\hline VHL S & 5-ACGGATGGGAGATTGAAGATTTCTGTGG-3 & 71,8 & 62 & NM_000551 & 4 \\
\hline VHL AS & 5-CTCTGAGAATGAGACACTTTGAAACTAAGG-3 & 66,8 & 62 & NM_000551 & 4 \\
\hline VEGF A S & 5-GCCTTCGCTTACTCTCAC-3 & 57,6 & 62 & NM_001025366 & 3 \\
\hline VEGF A AS & 5-GCTGCTTCTTCCAACAATG-3 & 61,0 & 62 & NM_001025366 & 3 \\
\hline IL $1 B S$ & 5-TGGCCCTAAACAGATGAAGTG-3 & 67,1 & 62 & NM_000576 & 3 \\
\hline IL $1 B$ AS & 5-GTAGTGGTGGTCGGAGATTCG-3 & 65,6 & 62 & NM_000576 & 3 \\
\hline WEE1 S & 5-CACACGCCCAAGAGTTTG-3 & 63,1 & 62 & NM_003390 & 3 \\
\hline WEE1 AS & 5-CCTGAGGAATGAAGCAACAA-3 & 62,8 & 62 & NM_003390 & 3 \\
\hline VEGFßS & 5-САTCATCAAACAGGACAGAGT-3 & 59,2 & 62 & NM_003377 & 3 \\
\hline VEGFßAS & 5-AAGAGCCAGTTGTAAGATGC-3 & 58,6 & 62 & NM_003377 & 3 \\
\hline PKM2 S & 5-GGACCTGAGATCCGAACT-3 & 59,2 & 62 & NM_182417 & 3 \\
\hline PKM2 AS & 5-TCCATGTAGGCGTTATCCA-3 & 61,5 & 62 & NM_182417 & 3 \\
\hline PDK1 S & 5-AGCATCAGAGCCATCATTG-3 & 61,5 & 62 & NM_002610 & 4 \\
\hline PDK1 AS & 5-GAGGTGGAAGGATTACTTGAG-3 & 59,2 & 62 & NM_002610 & 4 \\
\hline CASP3 S & 5-AAGCGAATCAATGGACTCTG-3 & 61,8 & 62 & NM_004346 & 4 \\
\hline CASP3 AS & 5-AGTTTCTGAATGTTTCCCTGAG-3 & 61,1 & 62 & NM_004346 & 4 \\
\hline CASP9 S & 5-CCAGACCAGTGGACATTG-3 & 60,1 & 62 & NM_001229 & 4 \\
\hline CASP9 AS & 5-CCGCAACTTCTCACAGTC-3 & 59,6 & 62 & NM_001229 & 4 \\
\hline HMBS S & 5-CACGATCCCGAGACTCTG-3 & 62,12 & 62 & NM_000190 & 4 \\
\hline HMBS AS & 5-GTTGCCCATCCTTCATAGC-3 & 62,0 & 62 & NM_000190 & 4 \\
\hline NFkB S & 5-CACCGTGTAAACCAAAGC-3 & 59,1 & 62 & NM_003998 & 3 \\
\hline NFkB AS & 5-TTATGAACCAAGAAAGGAAGC-3 & 59,7 & 62 & NM_003998 & 3 \\
\hline TP53 S & 5-GGGACGGAACAGCTTTGAGG-3 & 68,0 & 62 & NM_000546 & 3 \\
\hline TP53 AS & 5-TTCTTGCGGAGATTCTCTTCCT-3 & 68,7 & 62 & NM_000546 & 3 \\
\hline IL $6 \mathrm{~S}$ & 5-АССТGAAССТTССАAАGATG-3 & 60,5 & 62 & NM_000600.3 & 3 \\
\hline IL 6 AS & 5-ACTCCAAAAGACCAGTGATG-3 & 59,1 & 62 & NM_000600.3 & 3 \\
\hline IL $8 \mathrm{~S}$ & 5-TCCATAAGGCACAAACTTTCA-3 & 65,1 & 62 & NM_000584.3 & 3 \\
\hline IL 8 AS & 5-AATCAGGAAGGCTGCCAAGA-3 & 66,6 & 62 & NM_000584.3 & 3 \\
\hline BAX S & 5-AGGATCGAGCAGGGCGAATG-3 & 70,7 & 62 & NM_004324 & 3 \\
\hline BAX AS & 5-GACACTCGCTCAGCTTCTTGG-3 & 66,4 & 62 & NM_004324 & 3 \\
\hline GAP $43 \mathrm{~S}$ & 5-GCAATGTTCCGTTCATCTGA-3 & 63,7 & 62 & NM_001130064 & 3 \\
\hline GAP 43 AS & 5-CCTTAGAGCCGCAAGTTTAC-3 & 60,5 & 62 & NM_001130064 & 3 \\
\hline IL $26 \mathrm{~S}$ & 5-AAGCAACGATTCCAGAAGAC-3 & 60,9 & 62 & NM_018402 & 3 \\
\hline IL 26 AS & 5-TATGAAAGTCCTCCACAAAGC-3 & 60,7 & 62 & NM_018402 & 3 \\
\hline TSPAN 2 S & 5-CCTTGAGTGAATGCCTGTT-3 & 60,3 & 62 & NM_005725 & 3 \\
\hline TSPAN 2 AS & 5-TCTGGGAGCGAAATAGGTT-3 & 61,2 & 62 & NM_005725 & 3 \\
\hline TSPAN $13 \mathrm{~S}$ & 5-АTCTTCTTGTTCCTGATTGCTT-3 & 60,7 & 62 & NM_014399 & 3 \\
\hline TSPAN 13 AS & 5-CACTTGCCGTATTGTTCCA-3 & 62,2 & 62 & NM_014399 & 3 \\
\hline
\end{tabular}

Each probe contained a cell suspension with $5 \times 10^{5}$ cells in FACS buffer (PBS+1\% bovine serum albumin (Sigma Aldrich, Deisenhofen, Germany) + 0,1\% FCS (Cambrex Bio Science, Hopkinton, USA). The anti-human clusters of differentiation (CD) ) 4, 8, 14, 29, 34, 43, 44, 45, 56, 59, 71, 73, 90, 105, 106, 117, 135, 146, 166, 271, GD2, HLA ABC, HLA RPQ were added. After an incubation time of 20 minutes and two washing steps, the probe was ready for analysis. All antibodies were from BD Biosciences. The complete FACS analysis results are shown in Table 1.

\section{Quantitative Real Time PCR (RTq-PCR)}

The cDNA transcription was performed using Roche Transcriptor First Strand cDNA Synthesis Kit (Roche, Mannheim, Germany) according to the manufacturer's instructions. All primers were purchased from Sigma Aldrich (Sigma Aldrich, Deisenhofen, Germany). The complete list of the primer sequences can be seen in Table 2.

The RTq-PCR was performed with the Roche Light Cycler 2.0 (Roche, Mannheim, Germany) using the following protocol. 
Fig. 1. Relative expression ratios of gene associated with inflammation. (A) shows the raw data with corresponding p-values, (B) shows relative expression rates of $5 \mathrm{mM}$ lactate, (C) shows relative expression rates of 10 mM lacatate, (D) shows relative expression rates of $15 \mathrm{mM}$ lactate.

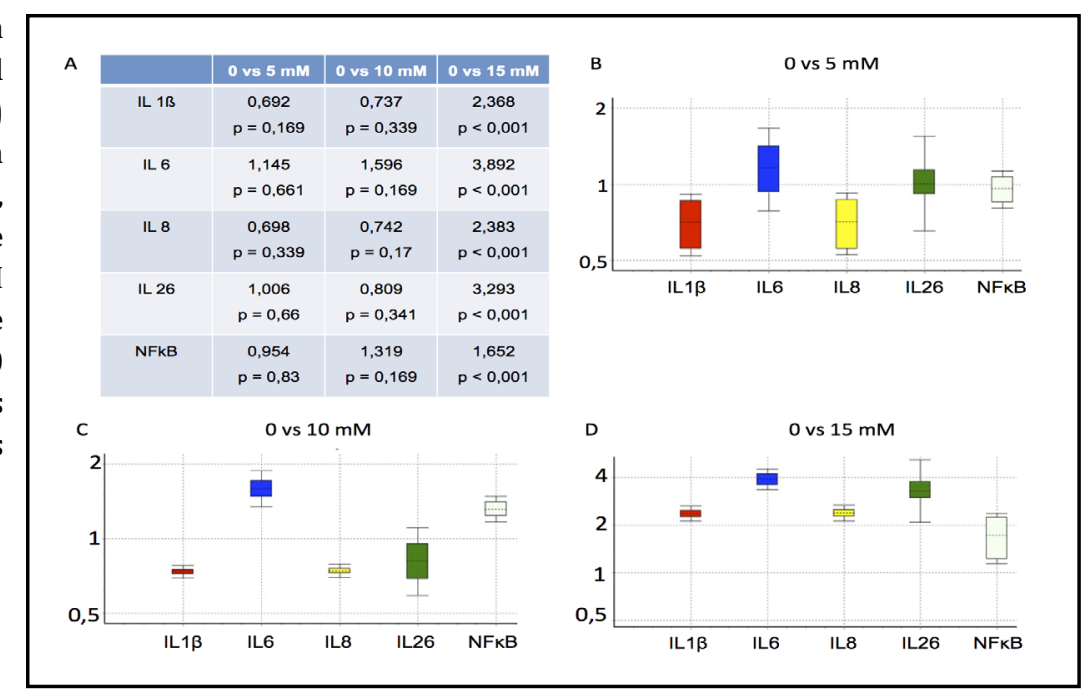

Fig. 2. Relative expression ratios of genes associated with proliferation and growth. (A) shows the raw data with corresponding p-values, (B) shows relative expression rates of $5 \mathrm{mM}$ lactate, (C) shows relative expression rates of 10 mM lacatate, (D) shows relative expression rates of $15 \mathrm{mM}$ lactate.

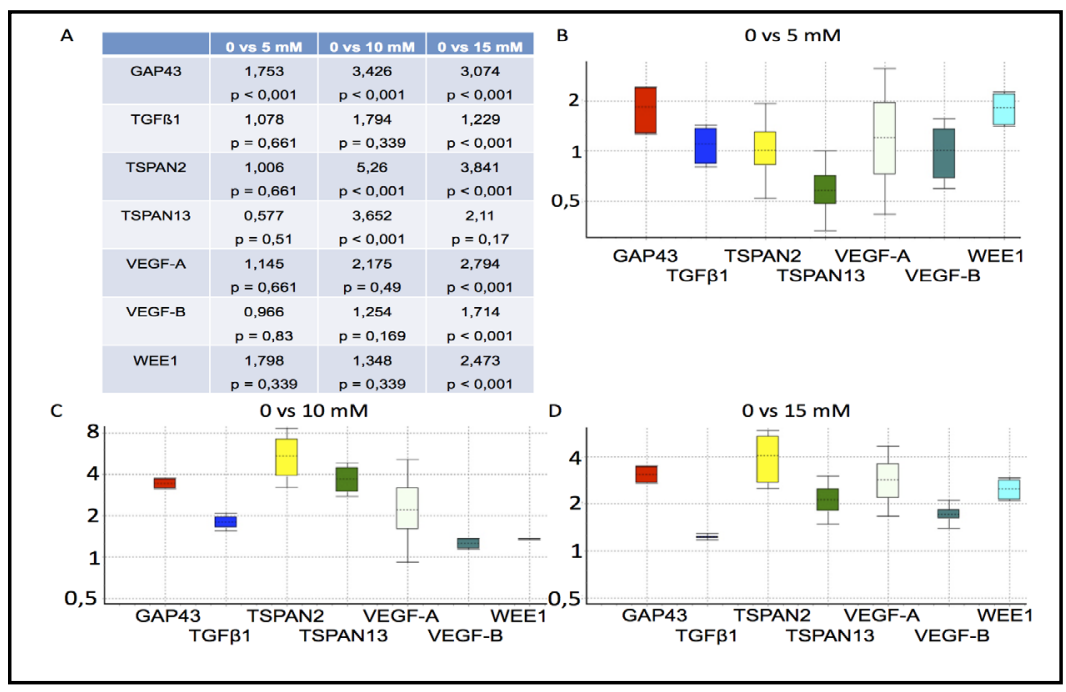

Pre-incubation for $300 \mathrm{~s}$ at $95^{\circ} \mathrm{C}$ for $1 \mathrm{cycle}\left(20^{\circ} \mathrm{C} / \mathrm{s}\right)$, amplification for $42 \mathrm{cycles}$ each with denaturation for $10 \mathrm{~s}$ at $95^{\circ} \mathrm{C}\left(20^{\circ} \mathrm{C} / \mathrm{s}\right)$, annealing for $5 \mathrm{~s}$ at $60^{\circ} \mathrm{C}\left(20^{\circ} \mathrm{C} / \mathrm{s}\right)$ and extension for $15 \mathrm{~s}$ at $72^{\circ} \mathrm{C}\left(20^{\circ} \mathrm{C} / \mathrm{s}\right)$, melting curve $15 \mathrm{~s}$ at $50^{\circ} \mathrm{C}\left(20^{\circ} \mathrm{C} / \mathrm{s}\right)$ then continuous ascent with $0,1^{\circ} \mathrm{C} / \mathrm{s}$ until $95^{\circ} \mathrm{C}$ for $1 \mathrm{cycle}$, followed by cooling $30 \mathrm{~s}$ at $40^{\circ} \mathrm{C}$ for 1 cycle $\left(20^{\circ} \mathrm{C} / \mathrm{s}\right)$.

Analysis was carried out using the relative quantification [10] and the relative expression software tool (RESTC) [11]. Human hydroxymethyl-bilane synthase (HMBS) was used as reference gene for the relative quantification [10].

\section{Results}

Microarray Results

The complete microarray data can be reviewed at GEO - GSE40205

\section{RTq-PCR Results}

For better illustration, the results were divided into the groups inflammation, proliferation and growth, apoptosis, hypoxia and glycolysis. 
Fig. 3. Relative expression ratios of genes associated with apoptosis. (A) shows the raw data with corresponding p-values, (B) shows relative expression rates of $5 \mathrm{mM}$ lactate, $(\mathrm{C})$ shows relative expression rates of 10 $\mathrm{mM}$ lacatate, (D) shows relative expression rates of $15 \mathrm{mM}$ lactate.

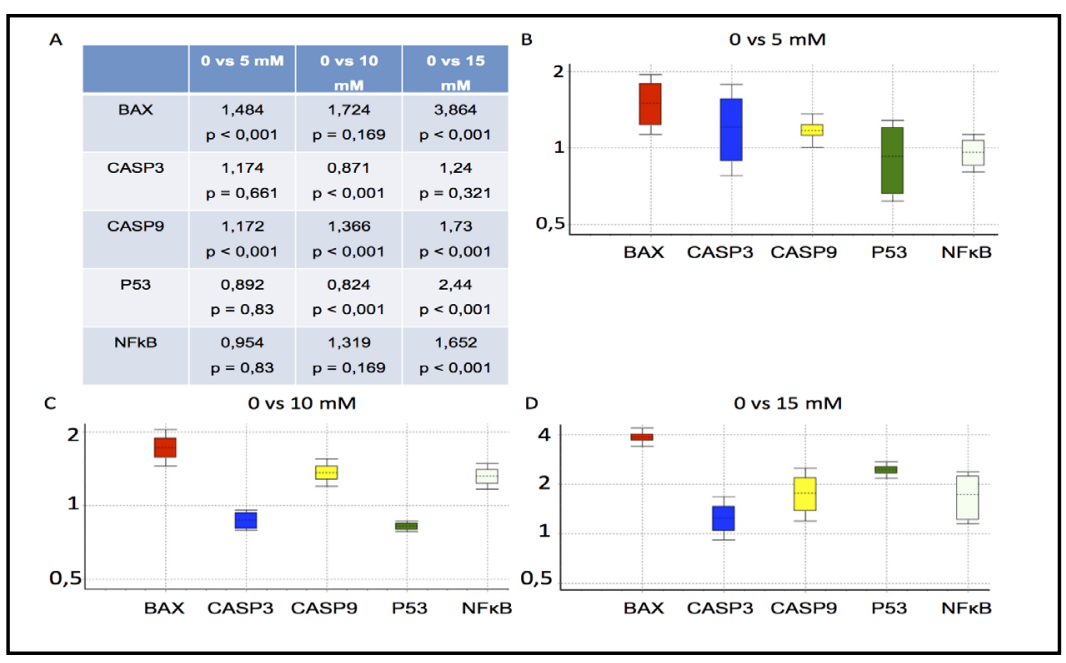

RTq-PCR - differential gene expression- inflammation

Figure 1 shows the differential gene expression of genes associated with inflammation. We were able to show that lactate in moderate concentrations of 5 and $10 \mathrm{mM}$ leads to a moderate down regulation of IL1ß $(0,692$-fold; $p=0,169)$ respectively 0,737 -fold; $p=0,339)$ and IL8 $(0,698$ fold; $p=0,339$ respectively 0,742 -fold; $p=0,17)$. In contrast, we were able to show that high lactate concentrations of $15 \mathrm{mM}$ lead to an up-regulation of the cytokines IL1ß (2,368-fold; $\mathrm{p}<0,001)$, IL6 (3,892-fold; $\mathrm{p}<0,001)$, IL8 (2,383-fold; $\mathrm{p}<0,001)$ and IL26 (3,293-fold; $\mathrm{p}<0,001)$.

\section{RTq-PCR - differential gene expression- proliferation and growth}

Figure 2 shows the differential gene expression of genes associated with proliferation and growth. Our analysis showed a moderate up-regulation of transforming growth factor $ß 1$ (TGFß1) at $10 \mathrm{mM}$ lactate $(1,794$-fold; $\mathrm{p}=0,339)$, whereas at 5 respectively $15 \mathrm{mM}$ we could not show any alteration. Additionally we investigated the Growth Associated Protein 43 (GAP43) and were able to demonstrate an up-regulation (1,753-fold; $p<0,001,3,426$-fold; $p<0,001,3,074$-fold; $p<0,001)$ in a dose dependant manner $(5,10,15 \mathrm{mM})$ with the highest expression rate change at $10 \mathrm{mM}$ lactate, similar to TGFß1. For tetraspanin 2 (TSPAN2) and tetraspanin 13 (TSPAN13) we could show a 5,26-fold; $\mathrm{p}<0,001$ respectively 3,652-fold; $\mathrm{p}<0,001$ up-regulation at $10 \mathrm{mM}$ lactate. For TSPAN2 also a 3,84-fold; $\mathrm{p}<0,001$ up-regulation at $15 \mathrm{mM}$ lactate. Additionally we were able to show a moderate up-regulation of WEE1-related kinases (WEE1) at $10 \mathrm{mM}$ lactate (1,348-fold; $\mathrm{p}=0,339)$, whereas at 5 respectively $15 \mathrm{mM}$ lactate the expression was even more up-regulated (1,798-fold; $\mathrm{p}=0,339$ respectively 2,473 -fold; $\mathrm{p}<0,001$ ). Also were able to show an increasing expression rate of vascular endothelial growth factor A (VEGF-A) (2,175-fold; $\mathrm{p}=0,49$ respectively 2,794-fold; $\mathrm{p}<0,001)$ at the lactate concentrations $10 \mathrm{mM}$ respectively $15 \mathrm{mM}$ and of vascular endothelial growth factor B (VEGF-B) $(1,714$-fold; $\mathrm{p}<0,001)$ at $15 \mathrm{mM}$.

\section{RTq-PCR - differential gene expression-apoptosis}

Figure 3 shows the differential gene expression of genes associated with apoptosis. We were able to show a moderate up-regulation of Bcl-2 associated X protein (BAX) (1,484-fold; $p<0,001$ respectively 1,724 -fold; $p=0,169$ )at the lactate concentrations $5 \mathrm{mM}$ respectively 10 $\mathrm{mM}$. At $10 \mathrm{mM}$ we could demonstrate a slight suppression of tumor protein 53 (p53) (0,824fold; $p=0,83)$ and effector caspase 3 (CASP3) $(0,871$-fold; $p<0,001)$. In contrast we found an up-regulation of BAX (3,864-fold; p<0,001), p53 (2,44-fold; p<0,001), Caspase 9 (CASP9) $(1,73$-fold; $p<0,001)$ and $N F \kappa B(1,652$-fold; $p<0,001)$ at $15 \mathrm{mM}$ lactate.

\section{RTq-PCR - differential gene expression - hypoxia}

Figure 4 shows the differential gene expression of genes associated with hypoxia. We could not show any up- or down-regulation of hypoxia inducible factor $1 \alpha$ (HIF1 $\alpha$ ) and von HippelLindau tumor suppressor protein (vHL). 
Fig. 4. Relative expression ratios of genes associated with hypoxia. (A) shows the raw data with corresponding p-values, (B) shows relative expression rates of $5 \mathrm{mM}$ lactate, (C) shows relative expression rates of 10 $\mathrm{mM}$ lacatate,(D) shows relative expression rates of $15 \mathrm{mM}$ lactate.

Fig. 5. Relative expression ratios of genes associated with glycolysis. (A) shows the raw data with corresponding p-values, (B) shows relative expression rates of $5 \mathrm{mM}$ lactate, (C) shows relative expression rates of 10 $\mathrm{mM}$ lacatate, (D) shows relative expression rates of $15 \mathrm{mM}$ lactate.
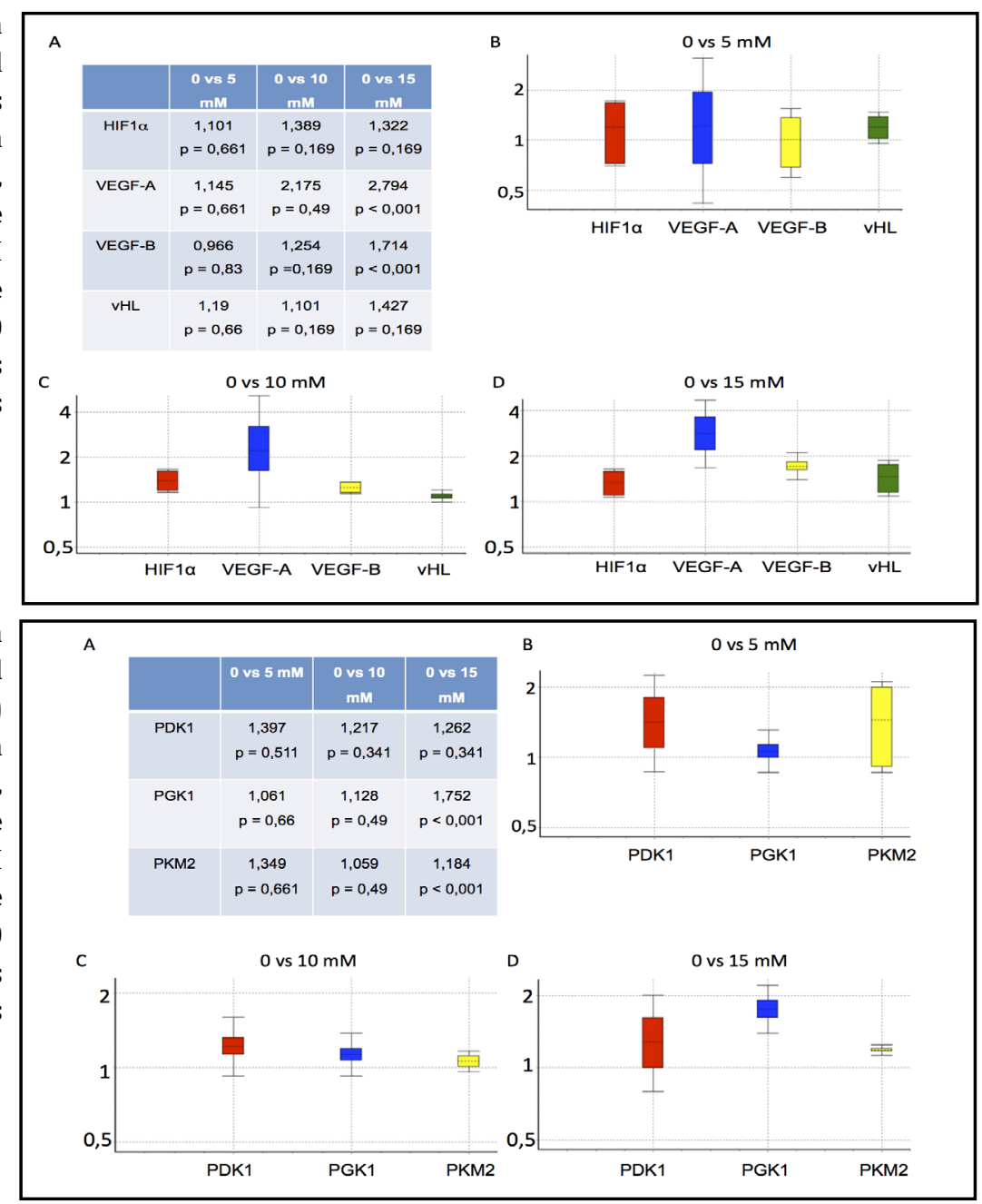

RTq-PCR - differential gene expression-glycolysis

Figure 5 shows the differential gene expression of genes associated with glycolysis. Again, we could not show any up- or down-regulation of pyruvate dehydrogenase kinase 1 (PDK1) and pyruvate kinase isoemzyme M2 (PKM2). Only a moderate up-regulation $(1,752$-fold; $\mathrm{p}<0,001)$ of phosphoglycerat kinase 1 (PGK1) and PKM2 $(1,184$-fold; $\mathrm{p}<0,001)$ at $15 \mathrm{mM}$ lactate could be found.

\section{Discussion}

This study was conducted to show the influence of lactate on the gene expression profile of human mesenchymal stem cells (hMSC). We were able to show that lactate alters gene expression in a dose dependent manner. Our research group previously could show that lactate does not change the cells' phenotype in terms of significant induction of alterations in expression of cell surface epitope patterns [12].

Human mesenchymal stem cells are multipotent cells which are present in adult bone marrow and almost every other tissue, and can differentiate to various mesenchymal tissues like bone, fat, muscle or marrow stroma [8].

Milovanova et al. demonstrated that lactate stimulates vasculogenic stem cells through an autocrine activation loop [7].

The link between wound healing and human mesenchymal stem cells (hMSC) has become a focus of attention lately. It has been shown that wound repair and even reconstitution of the wound 
bed can be accelerated by multipotent adult stem cells [9]. hMSCs enter the site of injury by a process called homing [13] and contribute to the wound healing process in two different ways. On the one hand hMSCs are able to differentiate into specific tissue related cells and therefore replace damaged tissue [14]. On the other hand a paracrine mode of action has been described, showing that hMSCs can lead to functional improvement after myocardial infarction [15].

Wounds are characterized by elevated tissue lactate concentrations [1]. Lately it has been shown that especially non-healing wounds appear with high wound fluid lactate levels [16]. In the past this accumulation of lactate was thought to be caused by tissue hypoxia, and therefore considered as an irrelevant metabolic by-product. Today some authors emphasize the multiple, hormone-like functions of lactate with some even using the term „lacterome“ [2]. Two well known effects of lactate are the stimulation of collagen synthesis [5] and vascular endothelial growth factor induced blood vessel formation [6] in vitro and in vivo. It has also been demonstrated that the oxygen supply has little impact on the lactate concentration [3], wound lactate levels remain high (5 - $15 \mathrm{mM}$ ) even under sufficient oxygenation [4].

Considering these facts, we investigated the role of lactate at different concentrations $(5,10$, $15 \mathrm{mM}$ ) on the differential gene expression of hMSCs. The wound healing process consists of the following phases: inflammation, proliferation, and tissue remodeling [17]. For better illustration, the results are divided into the groups inflammation, proliferation and growth, apoptosis, hypoxia and glycolysis and will be discussed separately.

After $24 \mathrm{~h}$ incubation of samples treated with lactate concentrations of 5 and $10 \mathrm{mM}$, antiapoptotic, anti-inflammatory and growth and proliferation promoting gene expression could be observed in comparison to high lactate concentrations of $15 \mathrm{mM}$ that led to the opposed effect, namely promoting apoptosis and inflammation.

\section{Inflammation}

The first phase of the wound healing process is characterized by the inflammatory response. Under physiological conditions this inflammatory phase abates during the regeneration, whereas a persisting inflammation can be found in chronic, non-healing wounds [16]. Major players in this early wound healing process are interleukin $1 \beta$ (IL1 $\beta$ ), interleukin 6 (IL6), interleukin 8 (IL8), and interleukin 12 (IL12) [18]. Interleukin 1 is a high-potency cytokine which is able to trigger an intense inflammatory reaction through for instance chemotaxis of neutrophils, acute phase proteins and interleukin 6 [19]. Interleukin 6 (IL6) is another major player of acute and chronic inflammation. IL6 is induced by the nuclear factor kappa light chain enhancer of activated b cells (NFKB) and used as a clinical marker for vascular inflammation [20]. Interleukin 8 (IL8), also a pro-inflammatory mediator, is important for chemotaxis of neutrophils. It also promotes proliferation of endothelial cells, inhibits apoptosis and takes regulatory action in angiogenic processes, whether physiological in wound healing or pathological in tumorgenesis and metastasis [21-23].

Interleukin 26 (IL26) is a member of the Interleukin 10 (IL10) family, which contribute to the wound healing process with their anti-inflammatory attributes [24].

We were able to show that lactate in moderate concentrations of 5 and $10 \mathrm{mM}$ leads to a moderate down regulation of IL1ß and IL8. In contrast, we were able to show that high lactate concentrations of $15 \mathrm{mM}$ lead to an up-regulation of the cytokines IL6, IL26, IL8. Our data suggest that with an increasing lactate concentration the expression rate of pro-inflammatory genes is up regulated.

\section{Proliferation and Growth}

The second phase of the wound healing process is characterized by proliferation and growth. We further investigated transforming growth factor 31 (TGFß1), a growth factor with multiple functions involved in processes like cell growth, proliferation, differentiation and apoptosis [21]. Analysis showed a moderate up-regulation at $10 \mathrm{mM}$ lactate, whereas at 5 respectively $15 \mathrm{mM}$ we could not show any alteration.

Additionally we investigated the Growth Associated Protein 43 (GAP43) a neuronspecific phosphoprotein, which plays a critical role in axon growth and synapse function during 
neurogenesis [25-27]. During neurogenesis, GAP43 is physiologically down-regulated [28]. Were able to demonstrate an up-regulation of GAP43 in a dose dependant manner $(5,10,15 \mathrm{mM})$ with the highest expression rate change at $10 \mathrm{mM}$ lactate, similar to TGFß1. This up-regulation of GAP43 suggesting neuronal plasticity and growth will have to be investigated further. This is not only a matterofparticularinterest in terms wound healing.

Tetraspanin 2 (TSPAN2) and tetraspanin 13 (TSPAN13) are members of the tetraspanin family [29]. These approximately 30 differentmembrane proteins are highly conserved in multicellular organisms [30]. They play key roles in processes like cell-cell-communication, signal transduction, cell motility and tissue-organization $[31,32]$. It could be exhibited that TSPAN24/CD151 knockout mice lacking TPSAN24 showed defective wound healing, primarily owing to impairment of the re-epithelialization process [33]. At $10 \mathrm{mM}$ lactate, we could show an up-regulation of TPSAN2 as well as of TSPAN13.

The function of the WEE1-related kinases is a highly conserved process that controls the timing of entry into mitosis. As early as 1978, Fantes and Nurse could show in fission yeast that WEE1 is part of a cell-size checkpoint that prevents entry into mitosis before cells have reached a critical size. Loss of WEE1 function causes fission yeast to enter mitosis before sufficient growth has occurred, leading to formation of daughter cells that are smaller than normal $[34,35]$. In contrast to normal cells that repair damaged DNA during the $\mathrm{G}_{1}$-arrest, cancer cells often have a deficient $G_{1}$-arrest and are therefore regulated largely via the $G_{2}$-arrest. Here, WEE1 kinase is the key molecule in maintaining $\mathrm{G}_{2}$-cell-cycle checkpoint arrest for premitotic DNA repair. An over-expression of WEE1 in various cancer types like glioblastoma [36] and breast cancer [37] has been reported. Other studies demonstrated decreased cancer cell viability, reduced tumor burden and improved survival after WEE1 inhibition $[36,38]$. It has been shown that MK-1775, a potent WEE1 inhibitor is able to achieve tumor regressions selectively in p53-deficient pancreatic cancer xenografts [39]. Recently Hong et al. could show that hypoxia induces the WEE1 expression both at mRNA and protein levels [40]. We found the expression of WEE1 under normoxicconditions only moderately up regulated at $10 \mathrm{mM}$ lactate, whereas at 5 respectively $15 \mathrm{mM}$ lactate the expression was even more up regulated.

As already described by Constant et al. we also were able to show an increasing expression rate of vascular endothelial growth factor Acorresponding toan increasing lactate concentration at 10 $\mathrm{mM}$ respectively $15 \mathrm{mM}$ [6]. In general our data show a considerable increase of genes associated with growth and proliferation predominantly at $10 \mathrm{mM}$ lactate.

\section{Apoptosis}

Apoptosis is a vital component of wound healing that is involved in the removal of inflammatory cells and the transformation of granulation tissue into scar tissue, whereas a dysregulationof the apoptotic process can lead to pathological forms of wound healing like hypertrophic scarring [41].

The Bcl-2 associated X protein (BAX) activation by the tumor protein 53 (p53) induces apoptosis [42]. The effector caspase 3 (CASP3) is the final common pathway of the extrinsic and intrinsic activated apoptosis resulting in DNA fragmentation, degradation of cytoskeletal and nuclear proteins [43]. At moderate lactate concentrations of 5 respectively $10 \mathrm{mM}$ we found predominantly anti-apoptotic expression rates. P53 co-factor BAX showed a moderate up-regulation. At $10 \mathrm{mM}$ we demonstrated a slight suppression of p53 and CASP3. In contrast we found more pro-apoptotic effects at $15 \mathrm{mM}$ lactate including up-regulations of BAX, p53, Caspase 9, and NFkB.

\section{Hypoxia}

Although the lactate concentration simulated a hypoxic environment, contrary to expectation, we could not show any up- or down-regulation of hypoxia inducible factor $1 \alpha$ (HIF $1 \alpha)$ and von Hippel-Lindau tumor suppressor protein (vHL) [44].

\section{Glycolysis}

Again, contrary to expectation, we could not show any up- or down-regulation in the glycolysis associated candidates pyruvate dehydrogenase kinase 1 (PDK1) and pyruvate kinase 
isoemzyme M2 (PKM2), even though lactate is the metabolic end-product of this pathway [45]. Only a moderate up-regulation of phosphoglycerat kinase 1 (PGK1) and PKM2at $15 \mathrm{mM}$ lactate could be found.

\section{Conclusion}

We are aware of the fact that these are gene expression rates and that the levels of the corresponding proteins need to be further investigated since various regulatory processes may occur during translation and post-translational modification.

Nevertheless our data suggest that lactate is able to modulate the gene expression of hMSCs involved in wound healing in a concentration dependent manner. Furthermore lactate might be involved in the regulation of processes like tumorgenesis and neuronal plasticity and growth. These data could be helpful for investigating new treatment strategies for chronic non-healing wounds as well as tumor therapy and neuronal plasticity or regeneration.

\section{References}

1 Hunt TK, Conolly WB, Aronson SB, Goldstein P: Anaerobic metabolism and wound healing: an hypothesis for the initiation and cessation of collagen synthesis in wounds. Am J Surg 1978;135: 28-32.

- Hashimoto T, Brooks GA: Mitochondrial lactate oxidation complex and an adaptive role for lactate production. Med Sci Sports Exerc 2008;40:486-494.

3 Gladden LB: Lactate metabolism: a new paradigm for the third millennium. J Physiol 2004;558:5-30.

-4 Ghani QP, Wagner S, Becker HD, Hunt TK, Hussain MZ: Regulatory role of lactate in wound repair. Methods Enzymol 2004;381:565-575.

5 Green H, Goldberg B: Collagen and Cell Protein Synthesis by an Estrablished Mammalian Fibroblast Line. Nature 1964;204: 47-49.

-6 Constant JS, Feng JJ, Zabel DD, Yuan H, Suh DY, Scheuenstuhl H, Hunt TK, Hussain MZ: Lactate elicits vascular endothelial growth factor from macrophages: a possible alternative to hypoxia. Wound Repair Regen 2000;8:353360.

7 Milovanova TN, Bhopale VM, Sorokina EM, Moore JS, Hunt TK, Hauer-Jensen M, Velazquez OC, Thom SR: Lactate stimulates vasculogenic stem cells via the thioredoxin system and engages an autocrine activation loop involving hypoxia-inducible factor 1. Mol Cell Biol 2008;28:6248-6261.

8 Pittenger MF, Mackay AM, Beck SC, Jaiswal RK, Douglas R, Mosca JD, Moorman MA, Simonetti DW, Craig S, Marshak DR: Multilineage potential of adult human mesenchymal stem cells. Science 1999;284:143-147.

9 Cha J, Falanga V: Stem cells in cutaneous wound healing. Clin Dermatol 2007;25:73-78.

10 Pfaffl MW: A new mathematical model for relative quantification in real-time RT-PCR. Nucleic Acids Res 2001;29:e45.

11 Pfaffl MW, Horgan GW, Dempfle L: Relative expression software tool (REST) for group-wise comparison and statistical analysis of relative expression results in real-time PCR. Nucleic Acids Res 2002;30:e36.

-12 Zieker D, Schäfer R, Glatzle J, Nieselt K, Coerper S, Kluba T, Northoff H, Königsrainer A, Hunt TK, Beckert S: Lactate modulates gene expression in human mesenchymal stem cells. Langenbecks Arch Surg 2008;393:297-301.

13 Körbling M, Katz RL, Khanna A, Ruifrok AC, Rondon G, Albitar M, Champlin RE, Estrov Z: Hepatocytes and epithelial cells of donor origin in recipients of peripheral-blood stem cells. N Engl J Med 2002;346:738-746.

14 Fox JM, Chamberlain G, Ashton BA, Middleton J: Recent advances into the understanding of mesenchymal stem cell trafficking. Br J Haematol 2007;137:491-502.

15 Gnecchi M, He H, Noiseux N, Liang OD, Zhang L, Morello F, Mu H, Melo LG, Pratt RE, Ingwall JS, Dzau VJ: Evidence supporting paracrine hypothesis for Akt-modified mesenchymal stem cell-mediated cardiac protection and functional improvement. FASEB J 2006;20:661-669.

-16 Löffler M, Zieker D, Weinreich J, Löb S, Königsrainer I, Symons S, Bühler S, Königsrainer A, Northoff H, Beckert S: Wound fluid lactate concentration: a helpful marker for diagnosing soft-tissue infection in diabetic foot ulcers? Preliminary findings. Diabet Med 2011;28: 175-178.

17 Werner S, Grose R: Regulation of wound healing by growth factors and cytokines. Physiol Rev 2003;83:835-870.

18 Koh TJ, DiPietro LA: Inflammation and wound healing: the role of the macrophage. Expert Rev Mol Med 2011;13:e23.

19 Dinarello CA: Blocking IL-1 in systemic inflammation. J Exp Med 2005;201:1355-1359. 


\section{Cellular Physiology $\quad$ Cell Physiol Biochem 2012;30:1547-1556 and Biochemistry \\ Schneider/Ateschrang/Königsrainer et al.: Lactate and hMSC}

20 Brasier AR: The nuclear factor-kappaB-interleukin-6 signalling pathway mediating vascular inflammation. Cardiovasc Res 2010;86:211-218.

-21 Li AG, Lu S, Han G, Hoot KE, Wang X: Role of TGFbeta in skin inflammation and carcinogenesis. Mol Carcinog 2006;45:389-396.

22 Li A, Dubey S, Varney ML, Dave BJ, Singh RK: IL-8 directly enhanced endothelial cell survival, proliferation, and matrix metalloproteinases production and regulated angiogenesis. J Immunol 2003;170:3369-3376.

23 Vlahopoulos S, Boldogh I, Casola A, Brasier AR: Nuclear factor-kappaB-dependent induction of interleukin-8 gene expression by tumor necrosis factor alpha: evidence for an antioxidant sensitive activating pathway distinct from nuclear translocation. Blood 1999;94:1878-1889.

24 Ouyang W, Rutz S, Crellin NK, Valdez PA, Hymowitz SG: Regulation and functions of the IL-10 family of cytokines in inflammation and disease. Annu Rev Immunol 2011;29:71-109.

25 Mahalik TJ, Carrier A, Owens GP, Clayton G: The expression of GAP43 mRNA during the late embryonic and early postnatal development of the CNS of the rat: an in situ hybridization study. Brain Res Dev Brain Res 1992;67:75-83.

26 Meiri KF, Saffell JL, Walsh FS, Doherty P: Neurite outgrowth stimulated by neural cell adhesion molecules requires growth-associated protein-43 (GAP-43) function and is associated with GAP-43 phosphorylation in growth cones. J Neurosci 1998;18:10429-10437.

27 Zhao J, Zhang L, Zhang Y, Shen Y: The differential regulation of Gap43 gene in the neuronal differentiation of P19 cells. J Cell Physiol 2012;227:2645-2653.

28 Skene JH: Axonal growth-associated proteins. Annu Rev Neurosci 1989;12:127-156.

29 Garcia-Espana A, Chung P, Sarkar IN, Stiner E, Sun T, Desalle R: Appearance of new tetraspanin genes during vertebrate evolution. Genomics 2008;91:326-334.

30 Huang S, Yuan S, Dong M, Su J, Yu C, Shen Y, Xie X, Yu Y, Yu X, Chen S, Zhang S, Pontarotti P, Xu A: The phylogenetic analysis of tetraspanins projects the evolution of cell-cell interactions from unicellular to multicellular organisms. Genomics 2005;86:674-684.

-31 Hemler ME: Tetraspanin proteins mediate cellular penetration, invasion, and fusion events and define a novel type of membrane microdomain. Annu Rev Cell Dev Biol 2003;19:397-422.

-32 Wright MD, Moseley GW, van Spriel AB: Tetraspanin microdomains in immune cell signalling and malignant disease. Tissue Antigens 2004;64:533-542.

-33 Cowin AJ, Adams D, Geary SM, Wright MD, Jones JCR, Ashman LK: Wound healing is defective in mice lacking tetraspanin CD151. J Invest Dermatol 2006;126:680-689.

34 Fantes PA, Nurse P: Control of the timing of cell division in fission yeast. Cell size mutants reveal a second control pathway. Exp Cell Res 1978;115:317-329.

-35 Kellogg DR: Wee1-dependent mechanisms required for coordination of cell growth and cell division. J Cell Sci 2003;116:4883-4890.

-36 Mir SE, Witt Hamer PC de, Krawczyk PM, Balaj L, an Claes, Niers JM, van Tilborg AAG, Zwinderman AH, Geerts D, Kaspers GJL, Peter Vandertop W, Cloos J, Tannous BA, Wesseling P, Aten JA, Noske DP, van Noorden CJF, Wurdinger T: In silico analysis of kinase expression identifies WEE1 as a gatekeeper against mitotic catastrophe in glioblastoma. Cancer Cell 2010;18:244-257.

- 37 Iorns E, Lord CJ, Grigoriadis A, McDonald S, Fenwick K, Mackay A, Mein CA, Natrajan R, Savage K, Tamber N, Reis-Filho JS, Turner NC, Ashworth A: Integrated functional, gene expression and genomic analysis for the identification of cancer targets. PLoS One 2009;4:e5120.

-38 De Witt Hamer PC de, Mir SE, Noske D, van Noorden CJF, Würdinger T: WEE1 kinase targeting combined with DNA-damaging cancer therapy catalyzes mitotic catastrophe. Clin Cancer Res 2011;17:4200-4207.

-39 Rajeshkumar NV, Oliveira E de, Ottenhof N, Watters J, Brooks D, Demuth T, Shumway SD, Mizuarai S, Hirai H, Maitra A, Hidalgo M: MK-1775, a potent Weel inhibitor, synergizes with gemcitabine to achieve tumor regressions, selectively in p53-deficient pancreatic cancer xenografts. Clin Cancer Res 2011;17:2799-2806.

-40 Hong KS, Kim HS, Kim SH, Lim DJ, Park JY, Kim SD: Hypoxia induces Weel expression and attenuates hydrogen peroxide-induced endothelial damage in MS1 cells. Exp Mol Med 2011;43:653-659.

41 Greenhalgh DG: The role of apoptosis in wound healing. Int J Biochem Cell Biol 1998;30:1019-1030.

42 Shabnam MS, Srinivasan R, Wali A, Majumdar S, Joshi K, Behera D: Expression of p53 protein and the apoptotic regulatory molecules Bcl-2, Bcl-XL, and Bax in locally advanced squamous cell carcinoma of the lung. Lung Cancer 2004;45:181-188.

43 Martinvalet D, Zhu P, Lieberman J: Granzyme A induces caspase-independent mitochondrial damage, a required first step for apoptosis. Immunity 2005;22: 355-370.

44 Haase VH: The VHL tumor suppressor: master regulator of HIF. Curr Pharm Des 2009;15:3895-903.

45 Gladden LB: A lactatic perspective on metabolism. Med Sci Sports Exerc 2008;40:477-485. 